\title{
EDIFICIOS PROTOINDUSTRIALES PARA LA PRODUCCIÓN DE VINO EN SICILIA. LOS PALMENTOS Y LAS BODEGAS DEL ETNA DESDE EL S. XVII AL XIX
}

\author{
(PROTO-INDUSTRIAL BUILDINGS FOR WINE PRODUCTION IN SICILY THE PALMENTI AND WINE \\ CELLARS SINCE XVII TO XIX CENTURIES)
}

Giovanni Cascone y Paola Pennisi, Instituto de Topografia e Infraestructuras Rurales. Univ. de Estudios de Catania Salvatore di Fazio, Departamento de Ciencias y Tecnologías Agroforestales y Ambientales. Univ. de Estudios de Reggio-Calabria

ITALIA

Fecha de recepción: $27-$ VI-97

\begin{abstract}
RESUMEN
En la región del Etna, entre los siglos XVII y XLX, la producción del vino empieza a hacerse de un modo protoindustrial. En tales fechas se construyen numerosas infraestructuras de grandes dimensiones para producir vino, denotando una gran especialización tecnológica y arquitectónica. Muchas de estas construcciones se usan aún hoy, manteniéndose en buen estado; otras, sin embargo, avanzan hacia el abandono y el deterioro. En el presente estudio se analizan las caracteristicas principales de las bodegas y de los "palmentos" que han llegado hasta nosotros. Se relacionan los aspectos arquitectónicos con los puramente funcionales y se dedica una atención especial a la maquinaria de prensado. Se detalla al final el estado actual en el que se encuentra este patrimonio arquitectónico y se discuten las razones que hoy dia animan a conservarlo y a volver a ponerlo en funcionamiento. Por último, se definen rápidamente los modos concretos y las propuestas para llevarlo a cabo.
\end{abstract}

\section{SUMMARY}

In the Etnian region, during XVII and XLX centuries wine production begins to be made in a proto-industrial way. Great industries for wine production are built in these dates with a great technological and architectural specialization. Many of these constructions are in use today with good conservation state, but others are abandonned or ruined. In this paper the main characteristics of the "palmenti" and wine cellars that yet exist are analysed. Architectural aspects are related with simple functionality aspects devoting special attention to the press machinery. The present state of this architectural patrimony and reasons to preserve and reuse it are discussed. Several ways and proposals to achieve this are defined at the end.

\section{El Etna: el volcán y el vino}

Sicilia es la principal región productora de vino de Italia y produce anualmente una media de $11.000 \mathrm{hl}$, equivalente al $17 \%$ de la producción nacional total. El Etna, que es el volcán más alto de toda Europa con sus $3.300 \mathrm{~m}$ de altitud y que domina la costa oriental siciliana, con su noble y ancestral tradición vinícola, es, en este aspecto, todavía en la actualidad, una de las principales áreas sicilianas.

A lo largo de los siglos, sobre el volcán y en lōs territorios a los pies del mismo, las constantes erupciones han traido muerte y destrucción, pero también han fertilizado en gran medida las tierras tocadas por la lava. Un clima 
favorable, una gran presencia de recursos acuíferos cerca de la superficie y la naturaleza del suelo han permitido que en las partes bajas del Etna se haya establecido el hombre junto con la viticultura y la producción de vino desde tiempos muy remotos. En torno al s.II a.C., en tiempos de los romanos, cuando en Sicilia se demandaban $540.000 \mathrm{hl}$ de vino y 22.000 hectáreas de tierras estaban cubiertas por vides, los vinos que se producían en los pies del Etna gozaban de un gran prestigio.

Hoy el Etna ofrece un gran atractivo agrario, muy ligado a la presencia arraigada de la cultura vinícola y del vino. La distribución actual del territorio manifiesta, sobre todo, las transformaciones que se realizaron en torno a los siglos XVII y XIX, cuando la producción del vino conquistó una gran relevancia económica y se introdujeron las primeros sistemas de producción protoindustriales. Las superficies cultivadas con vides se extienden en las colinas llegando hasta los 1.000 metros de altitud, en cotas en las que ya este tipo de planta no suele cultivarse. Las terrazas, construidas con muros de piedra de lava sin cal, demuestran las transformaciones del paisaje realizadas en esos dos siglos, siendo numerosos los antiguos palmentos (construcciones destinadas específicamente a la vinificación de la uva) y las bodegas, frecuentes en la región del Etna y que nos han llegado en buen estado, con la estructura intacta y todos los instrumentos y las máquinas originales. Hoy constituyen un documento, especialmente interesante, no sólo para los estudiosos de su arquitectura, sino también para esos numerosos visitantes y turistas que contemplan la embelesadora y terrible magnificencia del Etna, descubren su paisaje, recorren sus campos y catan sus vinos (Fig. 1).

En este estudio, después de tratar brevemente las circunstancias históricas que han facilitado el desarrollo en el Etna de la cultura vinícola y de la producción de vino entre los siglos XVIIy XIX, se analizan las peculiaridades tipológicas, arquitectónicas y estilísticas de los restos históricos destinados a producir y conservar el vino. En especial, se pone

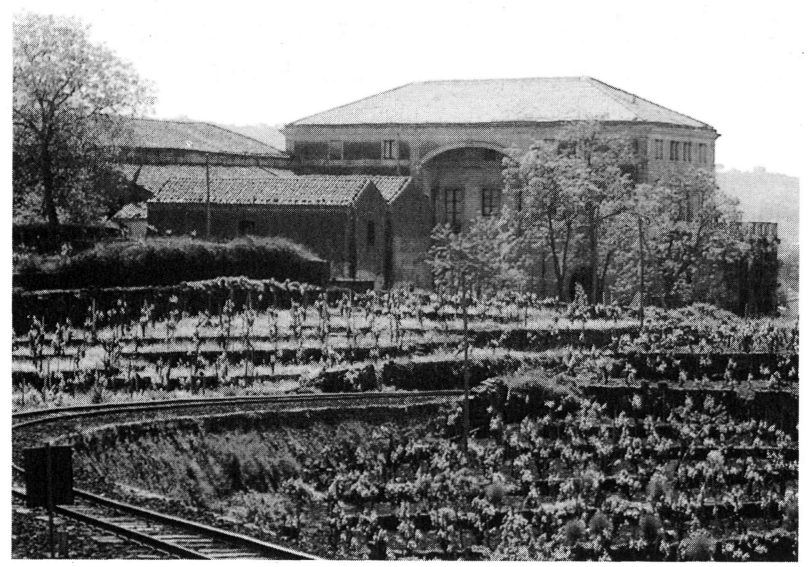

Fig. 1.- El paisaje aterrazado de la zona vinícola del Etna. Viñedo aterrazado y complejo vinícola con vivienda, "palmento" y bodega en el (c) Consejo Superior de terivestigaciones Científicas Licencia Creative Commons 3.0 España (by-nc) de manifiesto la compenetración entre el edificio y la maquinaria para fabricar el vino. El mismo edificio hace de máquina: con sus medidas, consigue transformar la energía potencial, relacionada con la ubicación del producto en cada una de las fases de producción, en energía cinética, haciendo posible que el mosto pase de un compartimento a otro, hasta los lugares de conservación, simplemente utilizando la gravedad.

Estudiando lo que nos llega del pasado, se comprende mejor el presente y se define el papel que la lógica arquitectónica, aplicada al trabajo, puede desempeñar para ayudarnos a imaginar de un modo distinto la actividad productiva y el desarrollo territorial. A estos aspectos se reserva la parte final del estudio. El modo de tratarlo intenta ser provocativo para destacar las contradicciones de la situación actual de ruina y abandono del patrimonio arquitectónico rural $\mathrm{y}$, junto con ellas, la necesidad de iniciar estrategias de miras amplias que conjuguen las exigencias de conservación con las de innovación y desarrollo.

\section{La producción y el comercio del vino en la región étnea entre los siglos XVII y XIX}

\subsection{La vid conquista el bosque y el monte}

En la región del Etna la viticultura y la producción del vino experimentan un fuerte desarrollo entre el ' 600 y el ' 800 ; en este período, Sicilia-por circunstancias- se encuentra bajo el dominio español. La actividad vitivinícola se concentra sobre todo en la zona nordoriental y en la parte baja oriental del Etna. En el condado de los Mascales, desde el s. XVI y a lo largo de todo el XVII, las tierras pertenecientes al Episcopado de Catania (Iachello, 1991) se distribuyen en concesiones enfitéuticas. Muchos de estos derechos de enfiteusis incluyen cláusulas específicas en las que se promueve el cultivo de vides y se prohibe la ganadería. La división en parcelas transforma rápidamente la organización del territorio agrario, que está caracterizado por la presencia de pequeñas y medianas posesiones de tierras en las que se cultivan vides y que están rodeadas de muros de piedra de lava sin cal para protegerse de los animales.

Las vides ganan gradualmente terrenos que antes estaban destinados a la ganadería y, desde la segunda mitad del s. XVII, también los bosques del Etna, llegando a sustituir casi completamente, a principios del s. XVIII, a la vegetación de montaña. De esta manera, la parte baja de la vertiente oriental del Etna y el condado de los Mascales, en especial, se convierten en la región siciliana más poblada de vides. Esta planta representará entre el 60 y el $70 \%$ de la superficie destinada a la agricultura (Iachello, 1991). El viñedo y la producción del vino octupan también cotas relativamente muy elevadas, por eneima de los $1.000 \mathrm{~m}$, arrebatando al terreno zonas abruptas, por medio de importantes trabajos de construcción de bancales que aún hoy son característicos del paisaje étneo (Sanfilippo, 1993). 
2.2 El comercio y el desarrollo protoindustrial de la producción vinicola del ' 800

Al desarrollo de la producción vinícola contribuye el crecimiento del comercio y del tráfico marítimo concentrados en el puerto de Riposto, que, dentro del Condado, ocupa un lugar céntrico a lo largo de la costa y baricéntrico con respecto a la distribución de los viñedos del Etna. El área costera en que se encuentra el puerto está conectada con las zonas de colinas y montañosas por medio de pendientes relativamente suaves y fáciles de recorrer. En el '700 el puerto de Riposto es muy visitado por los comerciantes genoveses y malteses, a los que les interesa comprar los productos agrícolas de la zona y, en especial, el vino.

El comercio del vino tiene un nuevo impulso a partir del 1806, gracias a la presencia temporal de los ingleses, que ocupan Sicilia estableciéndose con 25.000 hombres. La flota inglesa permite acabar definitivamente con los piratas que hasta entonces -y de forma insistente- habian atacado a los almacenes y bodegas de la zona a los pies del Etna, imprimiendo un nuevo empuje a la producción vinícola siciliana, cuyos principales consumidores son los mismos ingleses. El vino consigue hacer suyas esas características que responden a las exigencias de los clientes y de los comerciantes: elevado nivel de alcohol, fuerte tanicidad, gran estabilidad y capacidad de conservación durante la navegación (Sestini, 1812).

A lo largo de todo el ' 800 , los vinos de Sicilia y los del Etna en especial, son objeto de un intenso tráfico marítimo internacional. En 1853 en Sicilia constan 99.500 hectáreas de viñedos exclusivos y 55.284 hectáreas de viñedos arbolados. La superficie destinada a la vid en la provincia de Catania, formada en gran parte por la región étnea, asciende a 36.000 hectáreas de las cuales 17.000 son viñedos exclusivamente. Entre 1870 y 1885 , los viñedos franceses y de Italia septentrional se ven afectados por la filoxera lo que redunda en una gran demanda de vinos sicilianos. Como consecuencia de ello se produce un aumento enorme de la superficie destinada a la vid, hasta alcanzar, en 1885 , las 320.000 hectáreas. La primacía, con más de 92.000 hectáreas de viñedos, es de la provincia de Catania. La región étnea se convierte, de esta manera, en el área principal de producción vinícola de Sicilia y en una de las más importantes de todo el Mundo (Pastena, 1989).

Entre el ' 700 y el ' 800 , por lo tanto, la producción de vino adquiere completamente un carácter protoindustrial. Son diversos los factores que permiten definirla asi: la enorme inversiön destinada a viñedos y establecimientos de especialización vinícola; las dimensiones de la producción(por cantidad de uvas trabajadas o números de empleados); el compromiso por introducir un método racional en la producción del vino por medio de sistemas mecánicos y una precisa determinación funcional de las medidas de los edificios ligados a la producción; la creación de infraestructuras territoriales de almacenamiento y transporte.

En este espacio temporal los campos se cubren de bodegas y de numerosos edificios destinados a la producción de vino, los palmentos. Éstos, están presentes tanto en las pequeñas posesiones agrícolas como en las grandes fincas, donde es muy frecuente que alcancen importantes niveles de especialización tecnológica y dimensiones respetables. En los párrafos siguientes se describen las características principales de los edificios destinadas a la producción vinícola en la región étnea.

\section{Los palmentos y las bodegas del Etna}

\subsection{Desde el "palmento" al aire libre a los complejos vinicolas}

Palmento es el nombre que se da en Sicilia al conjunto de locales en que se realiza la producción del vino. En el palmento se recibe la uva, se estruja, fermenta el mosto y se prensan sus restos.

El término palmentum, cuya etimología es incierta, ya se utilizaba en la edad media, incluso en otras regiones del sur de Italia, como Puglia, Campania, Abruzzo y Basilicata. Probablemente viene del verbo latino "pavire"(machacar, pisar), a través del sustantivo "pavimentum"(suelo); de hecho, en dichas regiones la uva se pisaba sobre el suelo de una bañera especial, en cal y canto ${ }^{1}$.

En la zona del Etna, los modelos más rudimentarios de palmentos, que aún hoy se pueden ver, están formadas por pequeñas bañeras de mampostería construidas al aire libre y comunicadas, por medio de un canal de desagüe, con una cuba inferior para la fermentación, también fabricado de mampostería (La guzza et al., 1994). Si el territorio lo permitía, los palmentos se construían amparados por cuevas y cavidades naturales, para poder resguardar el producto de la lluvia; si no, se recurría a fabricar un cobertizo, sujetado por troncos de madera o por pequeños pilares de cal y canto, y recubierto con materiales vegetales o tejas de arcilla. Cuando en la viña habia otros edificios -como, por ejemplo, una casa de campo o los almacenes- el palmento se adosaba a uno de ellos, para así aprovecharse y cubrirlo más fácilmente, ya que se apoyaba, al menos en parte, en los muros perimetrales de otra estructura que ya existía.

Entre los siglos XVII y XVIII, cuando la difusión de viñedos por el territorio empezaba a experimentar un importante incremento, los palmentos, de simples construcciones al aire libre como las arriba descritas, evolucionaron hacia formas más complejas que preveian, en cualquier caso, que las bañeras para pisar la uva y las cubas ocupasen edificios especificos para ellas. En ellos se encuentra un departamento de prensado, caracterizado por 

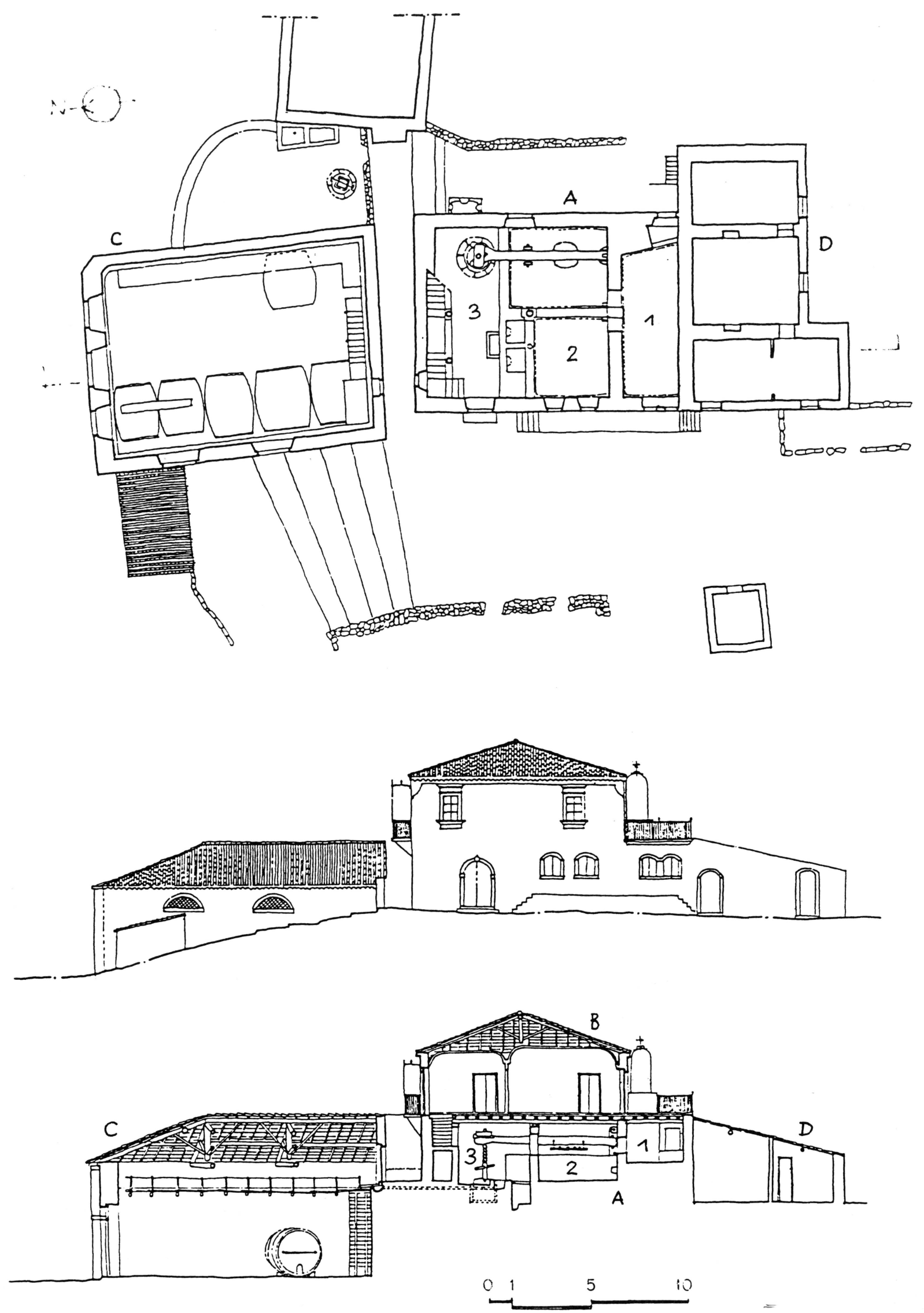

Fig. 2.- Típico complejo vinicola étneo en el territorio de Linguaglossa. Planta al nivel del suelo, alzado oeste y sección. El complejo constructivo está constituido por un cuerpo de fábrica que incluye el "palmento" (A), la vivienda (B), un cuerpo de fábrica parcialmente enterrado, correspondiente a la bodega (C) y un anejo rústico (D). En el "palmento" se distinguen: la zona de pisado (1), la cuba de fermentación (2) y el área de prensado (3). 
unas prensas fijas, empleadas, precisamente, para prensar el orujo.

\subsection{La organización del complejo arquitectónico en relación con el lugar}

Los palmentos que aún hoy, siendo numerosos, se pueden encontrar en el Etna, pertenecen a épocas posteriores al siglo XVII (Failla e Nicoloso Asmundo, 1984). En 1693, de hecho, una gran parte de Sicilia oriental fue devastada por un terremoto catastrófico que destruyó casi todos los edificios de entonces.

En la región del Etna es muy extraño que el palmento se presente como una construcción aislada. Está siempre unido a la residencia de los señores y la bodega, dentro de infraestructuras frecuentemente muy complejas, tanto bajo el aspecto de la distribución como bajo el de las dimensiones. Las distintas zonas funcionales de elaboración y conservación se encuentran, de hecho, a distintos niveles, como consecuencia de la necesidad de hacer pasar el mosto, a lo largo de las sucesivas fases de fabricación, valiéndose sólo de la fuerza de gravedad y de de una serie de oportunos sistemas de canalización. Por lo tanto, a alturas cada vez menores, se van situando, respectivamente, el lugar donde se pisa la uva, la cuba de fermentación, la zona de prensado y, por último, la bodega (Fig. 2).

La distribución del conjunto de edificios está, a su vez, condicionada por la necesidad de acceder fácilmente, tanto al primer nivel -donde se pisa la uva- para que los vendimiadores puedan descargar sin problemas, como al último, el de la bodega, para permitir que se pueda cargar sin dificultad el vino destinado a la venta. La pendiente natural del terreno y lo accidentado del territorio étneo se transforman, de esta manera, en una fuente para solucionar el problema planteado, la circulación interna y el paso de una fase a la siguiente. Sobre todo en las zonas altas de las colinas o de montaña, los edifícios diseñados para la producción del vino confirman la especial genialidad de quien realizó el proyecto o del constructor, en lo que respecta a la distribución, desde el punto de vista altimétrico y distributivo del edificio, por medio de una atenta elección del lugar y un completo aprovechamiento de las ventajas ofrecidas por él.

Otro factor fundamental, del que depende la organización de todo el conjunto, es el control ambiental en los locales en los que se conservará el vino. En el área del Etna este problema asume una especial importancia, ya sea por la elevada temperatura que alcanza el aire en verano, con niveles, en muchos casos, superiores a los $35^{\circ} \mathrm{C}$ o por la fuerte variación térmica que se registra entre el día y la noche $\left(15-20^{\circ} \mathrm{C}\right)$, en especial en las cotas más elevadas. La conservación del vino, sin embargo, exige condiciones termohigrométricas estables, con temperaturas entre los $10^{\circ} \mathrm{C}$ y $\operatorname{los} 15^{\circ} \mathrm{C}$. Para responder a estas necesidades el edificio de la bodega se cubría de tierra en dos o tres de sus lados (Fig. 3) y se orientaba hacia el norte, mientras que los frentes que se quedaban al descubierto tenían el espesor necesario como para garantizar una capacidad térmica suficiente como para protegerla del calor del verano y mantener estable la temperatura dentro del edificio. La construcción de las oportunas ventanas o rendijas en la parte alta de los muros perimetrales, en lados opuestos, confería, además, poca iluminación y una ventilación adecuada para mantener fresco el edificio, conservar la humedad dentro de unos niveles aceptables y alejar los gases producidos por la fermentación del mosto. Para conseguir este control termohigrométrico se valían muchas veces del suelo, hecho con tierra batida capaz de absorber la excesiva humedad y de la solera, fabricada con tejas de arcilla cocida, simplemente apoyadas sobre unos bordes supletorios, para lograr una ventilación añadida y evitar toda forma de condensación.

La presencia de viñedos y la estructura de la propiedad agrícola ha comportado que sobre la vertiente oriental del Etna, junto a una serie de pequeños centros urbanos, se localizase también otra forma de población que difícilmente se podía encontrar en otras partes de Sicilia.

Tanto en el caso de pequeñas viñas como en el de grandes posesiones de tierras, la residencia del propietario estaba siempre ligada al palmento y a la bodega. En las grandes posesiones dicha casa se convertía en una auténtica villa rural, donde el propietario y su familia pasaban el verano y supervisaban los trabajos de la vendimia. Estaba situada en una posición de dominio, por encima del palmento o la

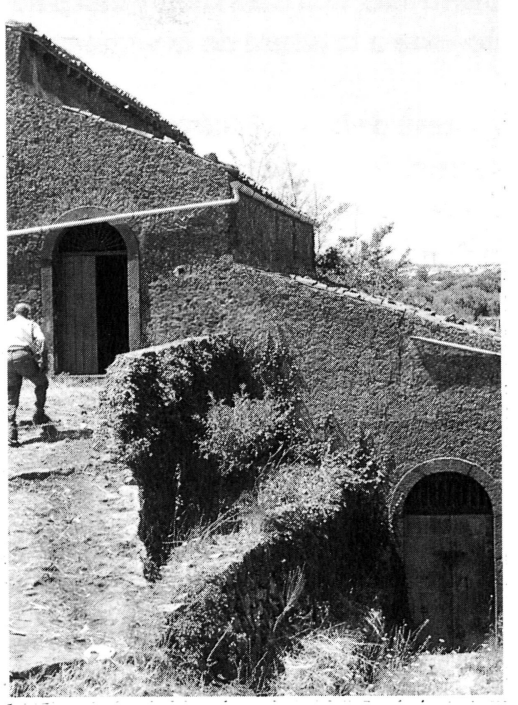

Fig. 3.- "Palmento" con bodega adyacente enel ámbito de la finca Polizzi, en el territorio de Randazzo. Destaca el enterramiento de la bodegay la notable diferencia de cota con el resto de la fábrica. 
cantina, para poder controlar con la vista lo que se hacía allí abajo. En algunos casos, una puerta interior ofrecía la posibilidad de acceder a la cantina directamente desde la casa señorial; una ventana o una mirilla en una habitación de servicio adyacente a los locales de fabricación del vino, hacían posible al propietario comprobar la ejecución de las operaciones correspondientes.

\section{Organización funcional y características constructi- vas del palmento}

\section{1 Área de recepción y prensado}

Como ya se ha remarcado, las uvas se transformaban dentro del ámbito de la misma empresa vinícola. Cada viña tenía su palmento, que estaba articulado en una serie de áreas funcionales que correspondían a cada una de las fases de fabricación (Fig. 4).

La de recepción de la uva y de prensado estaba situada en el interior del edificio, en el nivel más elevado y tenía que ser posible descargar fácilmente las uvas directamente desde el exterior. En las viñas, la vendimia se realizaba con grandes cestos de mimbre que llevaban los vendimiadores sobre sus espaldas, acercándose en fila hacia el palmento. La uva se descargaba entonces directamente sobre el suelo del área en que se prensaba, a través de grandes ventanas, normalmente colocadas de dos en dos.

Dependiendo de la pendiente natural del terreno, el nivel de prensado estaba en una posición más o menos elevada con respecto al de la viña. La consiguiente diferencia de alturas se salvaba gracias a escaleras construidas en el exterior y adosadas a uno de los muros perimetrales del palmento. Dichas escaleras contaban normalmente con dos rampas simétricas, una para subir y una para bajar, con un descansillo justo a la altura de la ventana de descarga.

El área de la prensa de la uva estaba formada por una parte cubierta de suelo, delimitada por unos parapetos con una altura cercana a $0,5 \mathrm{~m}$. La pavimentación se realizaba normalmente con lajas de piedra proveniente de la lava, trabajada "a bujarda" para darle esa rugosidad suficiente como para impedir que los prensadores se resbalasen. Hasta finales del Ochocientos y durante los primeros decenios del Novecientos la prensada se efectuaba todavía sin utilizar máquinas prensadoras, por considerar que éstas no le conferian una calidad suficiente al mosto. La inmediata separación de los racimos, efectuada entre los cilindros de la prensa y la excesiva presión que se ejercía sobre el ollejo, se consideraban perjudiciales para el vino(Caruso, 1869).

En los palmentos más grandes que todavía se pueden encontrar en la región de los Mascales, el área de prensado alcanzaba una capacidad comprendida entre los $12.000 \mathrm{y}$ los $15.000 \mathrm{~kg}$ diarios de uvas. Como a lo largo de una jornada un hombre podía prensar cerca de $2.000 \mathrm{~kg}$ de uvas, para esta operación se necesitaban, habitualmente, 6 u 8 empleados en total.

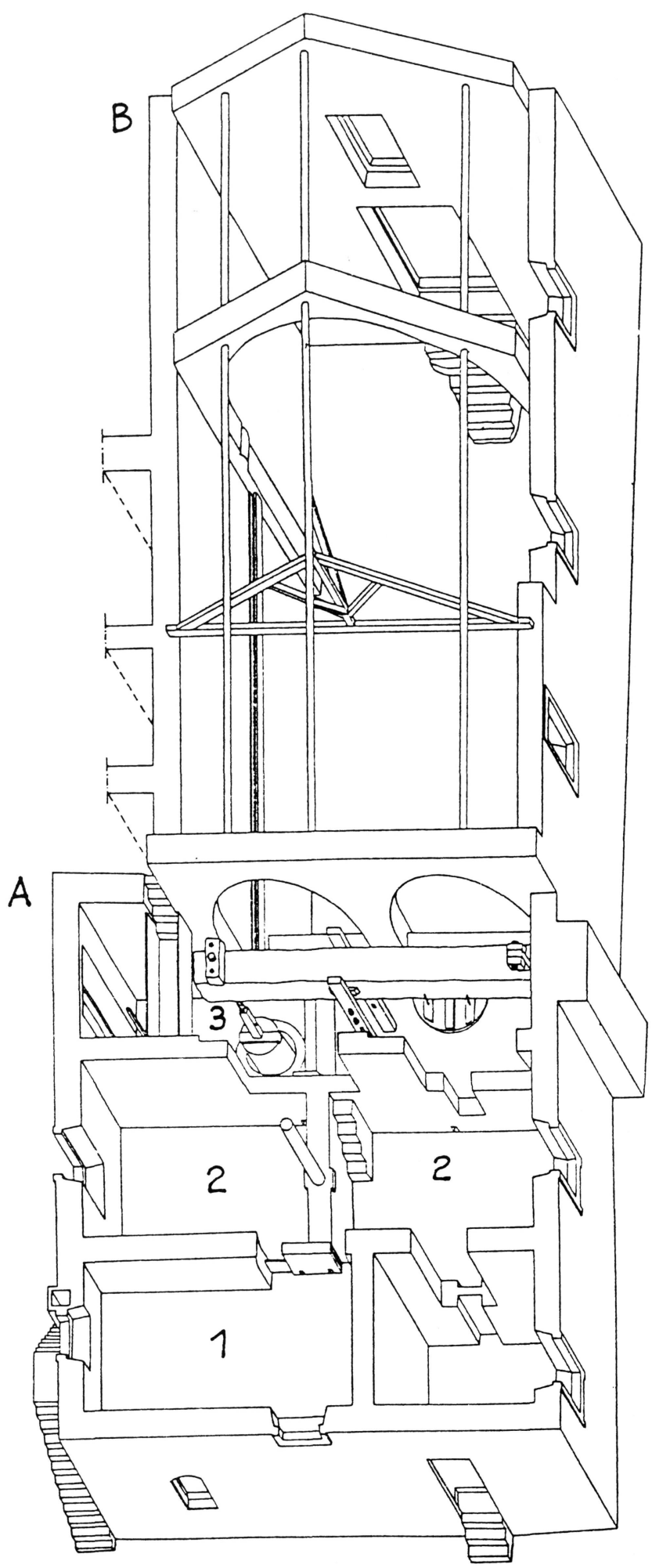

Fig. 4.- Vista axonométrica del "palmento" (A) y de la bodega (B) dentro del complejo vinicola de la finca $D^{\prime}$ A mico, en el territorio de $S$. Leonardello. El núcleo original fue edificado durante los siglos XV7I y XTTII. En el "palmento" se distinguen, en secuencia altimétrica, las siguientes áreas funcionales: 1) área de pisado, 2) cuba de fermentación y decantación (recibidora) y 3) zona de prensado de la vinaza (conso). 


\section{2 ('ubas de fermentación}

Por medio de las oportunas aberturas de las paredes de las cubas de prensado y por medio de canales de desagüe realizados con piedra de lava, el mosto pasaba entonces a las cubas inferiores que se llamaban "recibidores" (Fig. 5). Tales aberturas estaban dotadas de una tajaderas móviles, que se utilizaban para regular o impedir la circulación del orujo hasta los recibidores, según el tipo de vino a producir. Para los vinos tintos, los recibidores desempeñaban la función de cubas, al tratarse de una fermentación tumultuosa, mientras que para el mosto, que se reservaba a la producción del vino blanco, servían para una depuración parcial antes de enviarlo a un barril.

Los recibidores se realizaban con cal y canto, delimitados por pequeños muros de una altura de 1,3-1,6 m y se situaban a una diferencia de altura de $2-2,5 \mathrm{~m}$ con respecto al nivel de prensado. Con frecuencia ocupaban también el área que se encontraba por debajo de este último, estando, en tal caso, sostenido por una bóveda. Correspondiendo con los recibidores, en el muro perimetral del edificio se abrian orificios capaces de liberar el anhídrido carbónico que emanaba durante la fermentación; éste, en efecto, por pesar más que el aire, tendería, si no, a flotar entre la superficie libre del mosto y la bóveda que sostiene el nivel de prensado, dañando la salud de los trabajadores y poniendo en peligro la producción. Tanto el suelo como las paredes de las cubas-recibidores contaban con un revestimiento de una especie de hormigón, hecho a base de arena puzolana y arcilla, o bien con polvos y fragmentos provenientes del machaqueo de ladrillos y tejas. De esta manera se conseguían superficies suficientemente resistentes a la corrosión, que daban lugar a una baja reacción alcalina con el mosto en fase de fermentación. En las cubas, la fermentación oscilaba entre un período medio de 3 a 6 días, y en cualquier caso, nunca más de 10 .

En las cubas, los restos del prensado los distribuía -de manera uniforme- un trabajador por medio de uná azada. Este hombre se sumergía en la cuba atado a la cintura con una cuerda que sujetaba el operario que se encontraba en el nivel superior de la prensa, preparado para subir a su compañero en el caso de que resbalase o de que perdiese el conocimiento debido a la inhalación del anhídrido carbónico del mosto. De esta misma manera se realizaban, cada 24 horas, en los días sucesivos, los trabajos de compactación del orujo.

\subsection{Zona de prensado mecánico}

En la región del Etna la prensa que se emplea habitualmente para exprimir el orujo se denomina "conso" y el mismo nombre designa también la zona del edificio donde se realizan estas operaciones de prensado mecánico. Esta zona se encontraba al mismo nivel que los recibidores, justo debajo del de la prensa humana y adyacente a él, para

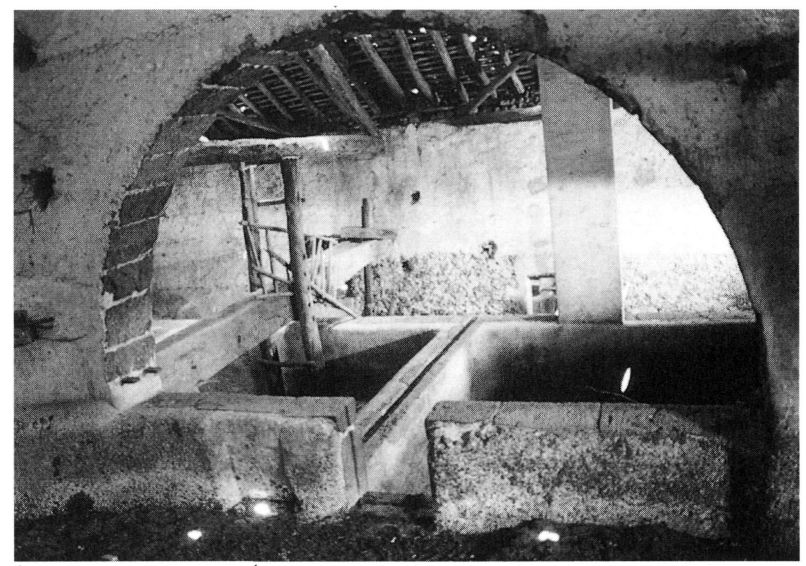

Fig. 5. - Vista del interior de un "palmento" étneo desde la zona de pisado. Destaca el área de prensado, con la prensa de madera.

poder transportar rápidamente el orujo que había que prensar. Está formada por una cuba rectangular y por un área operativa, desde la que se puede hacer funcionar la prensa mecánica.

Estas prensas, utilizadas por lo general hasta principios del presente sigloy que aún hoy se encuentran en los palmentos del Etna eran del tipo de viga de madera, con sistema de funcionamiento a base de palanca y tornillo, totalmente parecido a los que ya describió Plinio en el s. I d.C. y que se empleaba en época de los romanos, documentados, recientemente, por diversos hallazgos arqueológicos (Adams, 1984)

En una memoria científica, premiada en concurso por el Congreso Agrario de Catania de 1868, Girolamo Caruso describe los tornos del vino, esquematizándolos en el dibujo de la Figura 6.

El componente principal de la prensa es una viga de madera de encina (f) denominada "verga". En uno de los extremos la verga tiene la forma de "V" y está unida, con el oportuno enlace, a un tornillo (d) de madera en el cual está fijada, a su vez, una roca de lava (s), que normalmente tiene una forma de tronco de cono o de prisma, con un peso cercano a los $3.000 \mathrm{~kg}$. En el otro extremo la verga está unida, por medio de una cremallera móvil, a un palo vertical de madera (a), sólidamente incrustado en el suelo (b) y fijado a la pared con los llamados "gargoni". El palo de madera presenta unos agujeros (e) donde se alojan unas barras de hierro que sirven para impedir que el extremo (h) de la verga se desplace verticalmente. Del mismo modo, una escalera de madera (n), ubicada a una distancia del tornillo de más o menos un tercio de la longitud total de la verga y provista también de agujeros (o) para poner barras de hierro, además de para impedir que la vergase desplace lateralmente, permitía la existencia de un punto de apoyo intermedio, necesario para lograr la posición final de 

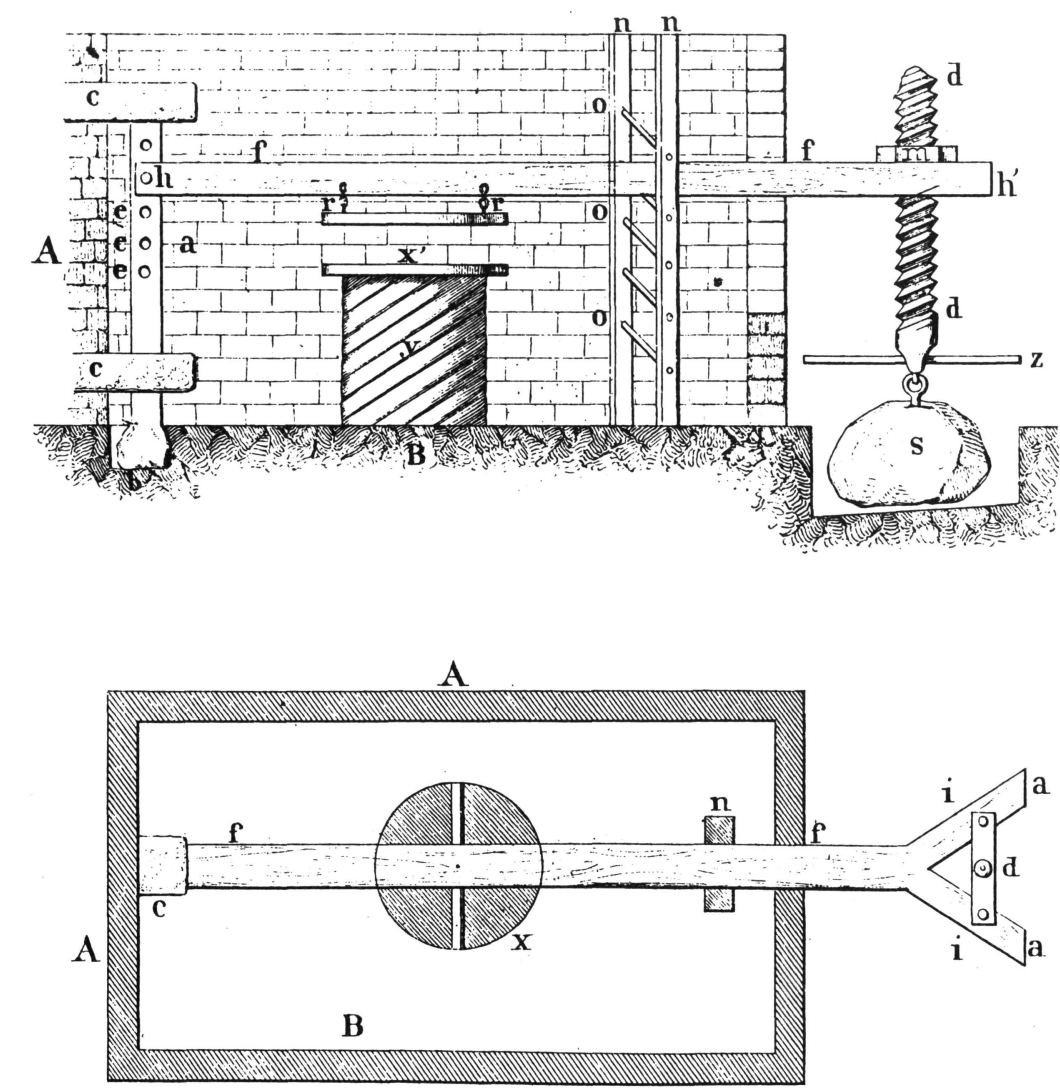

Fig. 6.- Representación esquemática de la prensa de viga en un "palmento" étneo (Caruso, 1869). Nomenclatura de los elementos: a) eje, c) anclaje, d) tornillo, e-ol huecos para los listones, n) escalera, f) viga, s) piedra, z) manivela.

prensado. El orujo que había que prensar se colocaba en el centro de la cuba de la prensa y se disponía siguiendo un cilindro (y), denominado "pasta", hecho con largas tiras de juncos. La pasta se situaba exactamente debajo del "tablero" $(\mathrm{x})$, un disco de madera suspendido en el aire y enganchado a la verga con dos cadenas cortas ( $r$ ), importante para distribuir, de un modo uniforme en la pasta, la presión de la prensa (Fig. 7).

El funcionamiento de la prensa requería la participación de un número de obreros que oscilaba entre 3 y 6 . Dependiendo de las dimensiones de la prensa y del peso de la piedra puesta en un extremo, de hecho, se precisaban entre dos y cuatro personas para accionar el tornillo, mientras que una o dos personas supervisaban la prensa mecánica, colocaban las barras de hierro en la escalera de sujeción y preparaban la pasta.

\section{El prensado del orujo y el mecanismo de la prensa}

Las operaciones del prensado empiezan con la colocación en la cuba de la casca y la formación de la pasta, envolviendo las cascas dentro de tiras de junco. Normalmente de disponen encima de la pasta unos discos de madera separados por ejes. Éstos, junto con el tablero de la prensa, desempeñan la función de ofrecer un contrapeso al descenso de la viga y a distribuir uniformemente sobre la pasta la presión transmitida por ella.

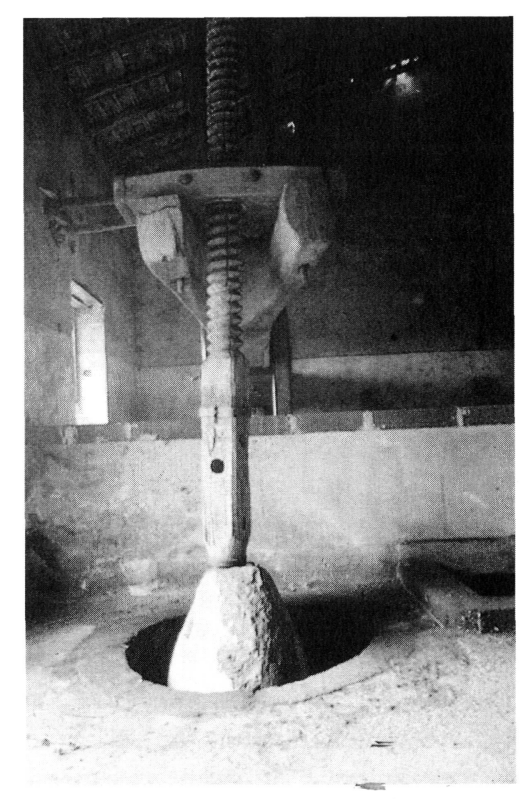

Hig. T. - Tista del extremo de la prensa de'viga con la piedra y la manivela. 
Las sucesivas fases de funcionamiento de la prensa se muestran en la Fig. 8. En un principio la prensa se encuentra en una posición de descanso, con la viga en horizontal por encima, apoyada sobre las barras de hierro de la escalera y del palo del extremo. Se procede entonces a bajar la viga, para llevar la prensa a la posición de prensado.

Mediante la rotación en sentido horario del tornillo de madera (Fig. 6) y la oposición, que viene a determinarse con las acanaladuras del tornillo, baja el extremo ahorquillado de la viga (A). La barra de la escalera hace de quicio y el extremo opuesto, libre en la parte superior, se eleva. Hecho esto, se puede remover la barra sobre la que dicho extremo se apoyaba anteriormente y colocarla en los agujeros, inmediatamente por debajo del eje.
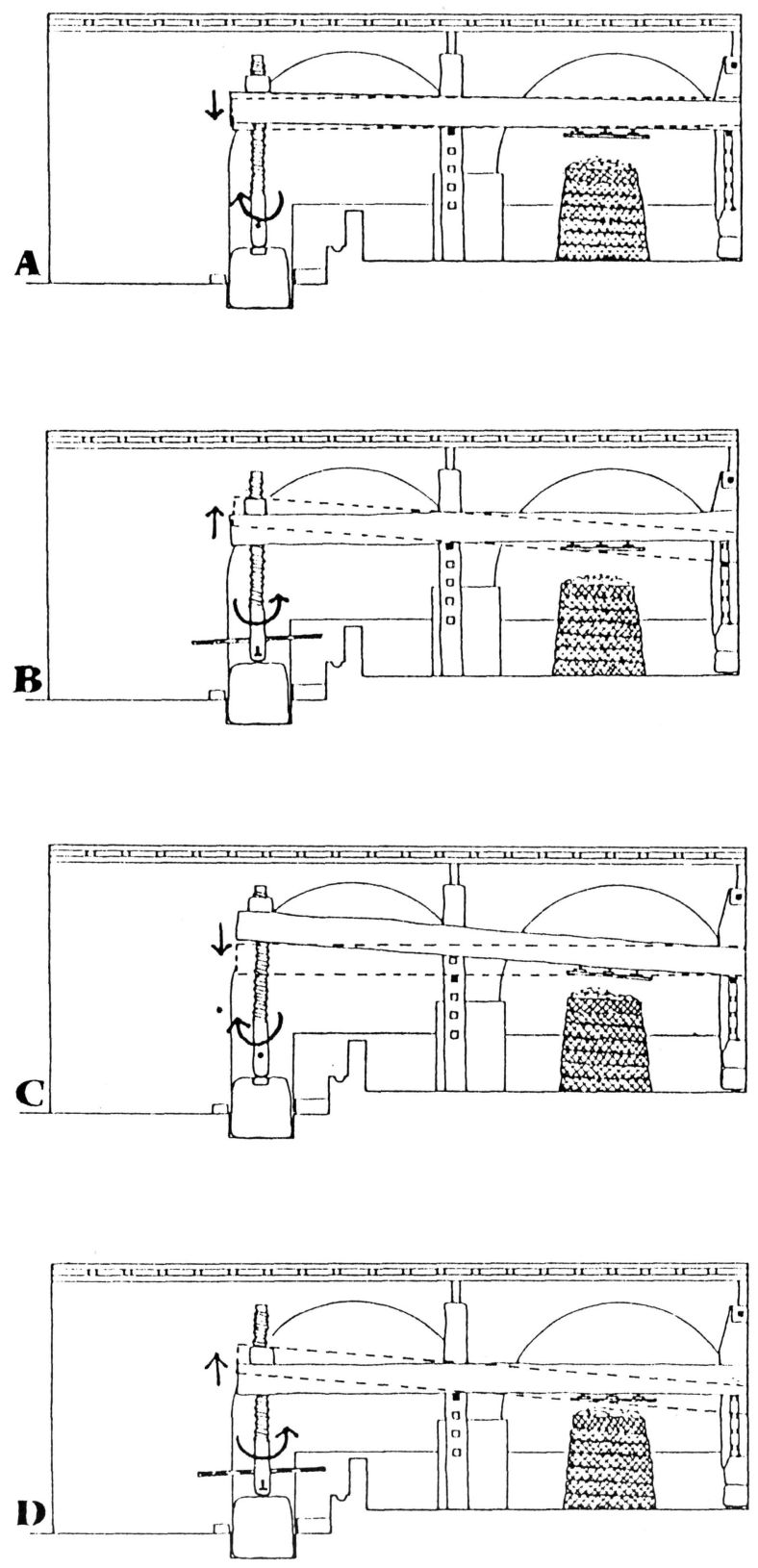

(c) Consejo Superior de Investigaciones Científicas Licencia Creative Commons 3.0 España (by-nc)
Entonces se hace girar el tornillo en sentido antihorario(B) hasta que el otro extremo se apoye sobre la nueva posición de la barra del eje, prosiguiéndose la rotación hasta levantar la viga con respecto al punto de apoyo de la escalera. Entonces se mueve la barra de la escalera, colocándola en los agujeros inferiores y se invierte el sentido de la rotación del tornillo (C) hasta volver a la posición de apoyo sobre la escalera.

Las operaciones descritas hasta aquí se pueden repetir sucesivamente, en la misma secuencia, haciendo descender la viga hasta la posición de prensado, o bien con el tablero de la prensa presionando encima de la pasta y eliminando el punto de apoyo que corresponde a la escalera (E).
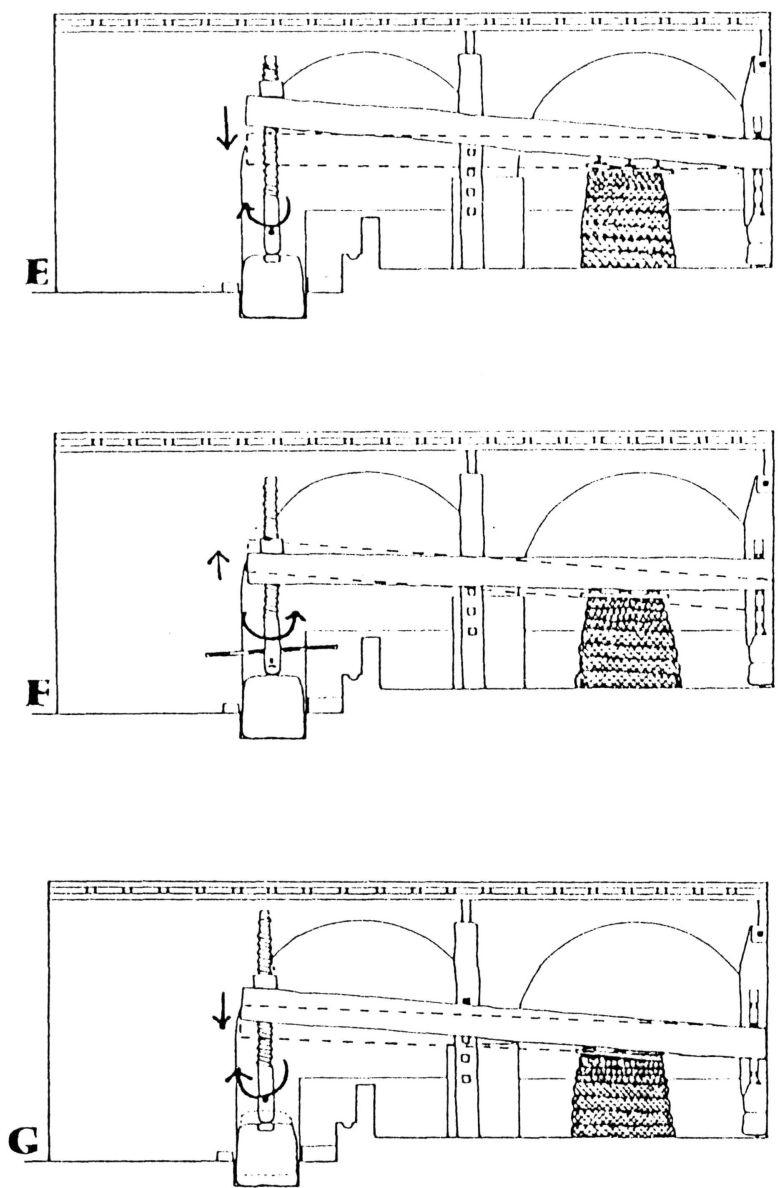

Fig. 8.- Secuencia de las fases de accionamiento de la prensa de viga. 
En la posición de prensado, la barra del eje hay que colocarla por encima de la cabecera de la viga, para impedir que se desplace hacia arriba. El tornillo hay que girarlo entonces en sentido antihorario $(\mathrm{F})$, utilizando una manivela a dos brazos; el resultado es la presión que se ejerce sobre la pasta, dependiendo de cuánto se aplasten las cascas, la extracción del mosto. También correspondiendo con la escalera, en esta fase, se pone una barra justo encima de la viga, con el fin de conseguir una presión más uniforme por medio de una alternancia de los movimientos del tornillo, evitando, así, el riesgo de que la viga se empine. A medida que las cascas se prensan, aumenta la resistencia que ofrece la pasta a la presión conseguida por medio del tornillo. Llegará un momento en que la pasta no descenderá más y el movimiento del tornillo sólo conseguirá levantar la piedra a la que está unido (G). Se hace de tal modo que la piedra se levante lo más posible, dejando, entonces, la prensa en esta posición durante más o menos dos horas, para que la presión ejercida en ese tiempo exprima de un mode suave y prolongado. Así se consigue exprimir por primera vez el orujo. Después de haber soltado la viga de los límites superiores, actuando sobre el tornillo se eleva el extremo, para poder quitar las tiras a la pasta. Se pasa entonces a cortar la pasta en todos los sentidos, a recomponer el cúmulo de las cascas y a vendarlo nuevamente. Entonces se acciona la prensa como se ha descrito anteriormente, prosiguiendo con la segunda y, a veces, con la tercera prensada.

Como durante la última fase de prensado mecánico el eje vertical de encabezamiento está sujeto a numerosos esfuerzos, transmitidos a la mampostería por medio del mecanismo para encajarlo, y en especial por los "gangoni", era una buena solución constructiva la de fabricar muros de mucho espesor en la zona de prensado o fabricar un muro contrafuerte que corresponda con el eje. En este último caso, la colocación de la prensa se podía adivinar inmediatamente observando el edificio desde el exterior.

El mosto que venía de la prensa mecánica de las cascas se fermentaba y conservaba en un lugar diferente del que provenía del prensado con los pies. Casi nunca se mezclaba y, como mucho, se usaba en esos casos el derivado de la primera prensada.

La eficiencia extractiva del sistema de prensado mecánico empleado se pone en evidencia en la ya citada memoria de Caruso, donde, a propósito de las prensas étneas alaba también la capacidad productiva y el ahorro de mano de obra, con todo lo que significaba con respecto a otros sistemas que se usaban en la misma época, o que se anunciaban como innovadores, como, por ejemplo, la prensa de percusión de Revillon o la llamada "prensa calabresa" 2

Su sencillez de funcionamiento y los resultados que permitían conseguir, representan, además, la razón de que las prensas aquí descritas se hayan mantenido a lo largo del tiempo y que desde la antiguedad clásica hasta nuestros días hayan mantenido inalteradas sus características constructivas fundamentales y hayan experimentado una sorprendente y constante ${ }^{3}$ utilización.

En los palmentos más grandes de los que todavía hoy se conservan, aún se pueden localizar dos o tres áreas de prensado, con otras tantas prensas de vino. Esta solución se adoptaba cuando se tenían que trabajar grandes cantidades de uva, también por cuenta de terceros y cuando se necesitaba distinguir los métodos de vinificación.

\subsection{La bodega}

Gracias a la peculiar distribución de las alturas del palmento, el mosto se podía llevar directamente desde las cubas hasta la bodega por medio de canalizaciones de piedra, de origen volcánico, que corrían alrededor de los muros perimetrales y que tenían bocas de salida correspondiendo con los toneles. En la embocadura de los canalillos se ponían filtros para eliminar los residuos y las impurezas de mayores dimensiones.

En la segunda mitad del Ochocientos, es decir, en el período en que la producción de vino en la región del Etna alcanza posiciones importantes y características protoindustriales, las bodegas se dividian, a grandes rasgos, según tres tipos de capacidades: las pequeñas contenían cerca de $70 \mathrm{hl}$ de vino, las medianas $100 \mathrm{hl}$ y las grandes $200 \mathrm{hl}$. En las bodegas de mayor capacidad el problema arquitectónico tenía una importancia especial (Cascone et al., 1994). La construcción de edificios de gran luz, con altura hasta el techo de incluso $8 \mathrm{~m}$, sin buhardillas ni divisiones internas, en una zona especialmente expuesta al riesgo, al tratarse de un área sísmica como la del Etna, necesitaba una especial atención, en razón del valor -por su naturaleza y su cantidad- del producto que conservaba en su interior.

Un especial cuidado se dedicaba a todos los detalles relacionados con el comportamiento monolítico de los muros, de modo que reaccionase bien ante los esfuerzos horizontales. Los muros tenían un gran espesor, incluso más de un metro; esto tenía como fin limitar la debilidad estructural y garantizar una mayor capacidad térmica. Se realizaban con bloques de piedra de lava regular y tallada, unidos con malla y alternados con líneas únicas o dobles de ladrillos para dar regularidad. Estas líneas se colocaban normalmente cada dos filas de bloques de piedras; a veces, en los edificios de estructura más pesa$\mathrm{da}$, se alternaba una fila de piedras con una de ladrillos o cuadrados del mismo material. Se tenía un especial cuidado con la manera de sujetar los bloques de piedra. Con frecuencia se usaban bloques colocados transversalmente para tener sujetos los lados interno y externo del muro. 
En las bodegas, normalmente, el techo es a dos aguas o, en la mayoría de los casos, en pabellón, con una estructura formada por vigas de madera. Éstas, presentan con frecuencia una distribución espacial de paraguas, con dos segmentos que unen la base de la viga vertical con las diagonales, para evitar la inflexión de estas últimas. Muchas veces la estructura triangular de las vigas que sujetan el techo no se apoya directamente sobre el muro, sino sobre el "durmiente": una viga que hace de borde, también de madera, que tiene la función de distribuir el peso de la techumbre entre todo el muro perimetral. Además, en el punto de apoyo la estructura triangular de las vigas se veía reforzada por elementos añadidos, para aumentar la superficie que soporta el peso y reducir el empuje. Cuando la luz que había que cubrir era muy amplia, o en las zonas en las que no había vigas de madera suficientemente grandes, se construían apoyos intermedios, formados por pilares de piedra de lava.

\section{Caracteres formales y estilísticos de los complejos vinícolas étneos}

Los edificios de la región vinícola del Etna son el fruto de una tradición que desciende de la "civilización de la lava". La piedra de la lava es, de hecho, el material de construcción que se usa principalmente y que da unidad al paisaje construido, integrándolo visiblemente en el paisaje natural. Esta piedra se encuentra por todas partes, siendo muy utilizada en los siguientes casos: en los muros, en las exposiciones de puertas y ventanas, en la pavimentación interna y externa, en las escaleras, en los pequeños muros que hacen de recinto y en las terrazas.

Se trata de una piedra basáltica de color gris-negro, dura de trabajar, pero de gran resistencia y durabilidad, con una resistencia a la compresión de más de $1.200 \mathrm{~kg} / \mathrm{cm}^{2}$. Se puede disponer de ella muy fácilmente en todo el territorio que rodea el volcán. Las rocas volcánicas, que muchas veces salen a la superficie, caracterizan gran parte del paisaje agrícola, incluso en las cotas más bajas, convirtiéndose en el elemento dominante a partir de los $1.500 \mathrm{~m}$ de cota.

En los edificios destinados específicamente a la producción de vino los caracteres formales descienden directamente de los funcionales (Failla et al., 1987; Failla, 1995). Los palmentos se pueden reconocer desde el exterior por los siguientes elementos constantes: escalera exterior de doble rampa; ventanas de descarga de las uvas, de dos en dos, a veces muy cercanas entre sí o incluso adyacentes; amplia puerta de entrada coincidiendo con la zona de prensado; ventanillas bajas de ventilación, a la altura de las cubas de fermentación (Fig. 9). Del mismo modo también las bodegas se pueden reconocer por lo siguiente: complejo de doble altura; aberturas de ventilación sin postigo y protegidas por rejas de hierro, situadas en la parte alta de los muros en los lados más largos del edificio; amplia puerta de entrada cubierta por un portal de piedra volcánica, normalmente poco ornamentada.

Las casas de los señores presentan también peculiaridades (Palumbo,1991). Son parte de cuerpos arquitectónicos, normalmente a dos niveles. La zona residencial se halla casi siempre en el primer nivel, mientras que en el piso bajo se encuentran dependencias del servicio, funcionales para la actividad agrícola y de transformación, como, por ejemplo, los palmentos y los almacenes. Los edificios tienen normalmente una forma compacta, techo a pabellón, supliendo-los característicos arcos- las funciones de sujeción de la terraza o de una galería (Fig. 10).

Mientras que en los palmentos y en las bodegas los elementos de terminación y decorativos externos prácticamente no existen y las referencias formales se refieren principalmente a los modos de expresar la tradición popu-

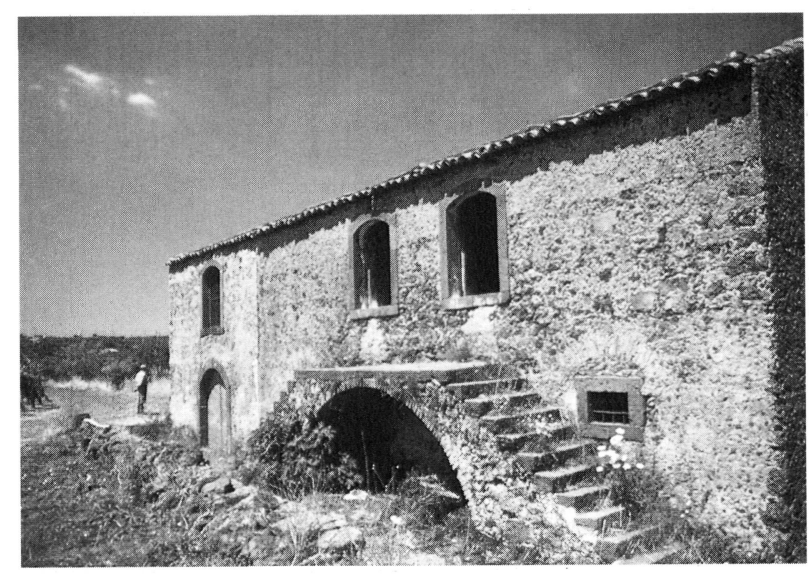

Fig. 9.- "Paimento" en el territorio de Randazzo. Destaca la escalera externa de doble rampa, la ventana para introducir la uva en la zona de pisado y la ventanilla de aireación correspondiente a la cuba de fermentación.

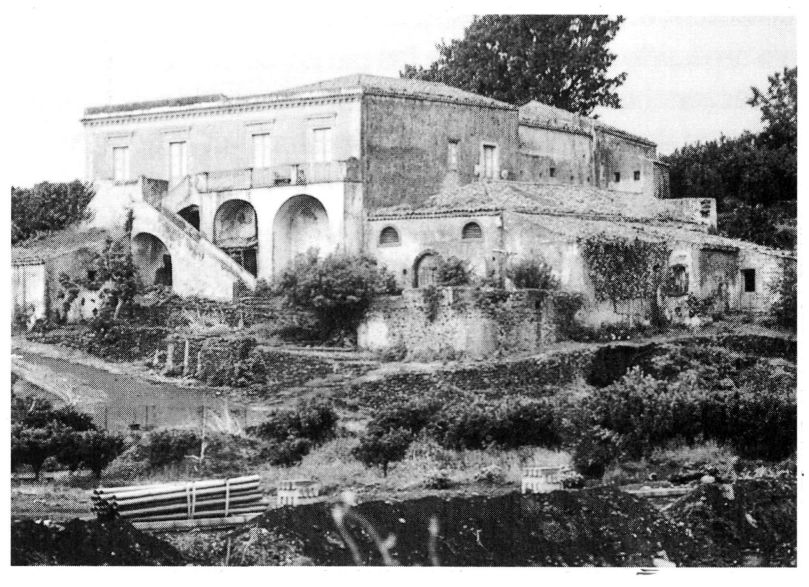

Fig. 10.- Complejo vinicola en el territorio del Piamonte étneo. Son evidentes los arcos de sostenimiento de la planta de la vivienda y la bodega, con una amplia entrada y la caracteristica ventana semicircular. 


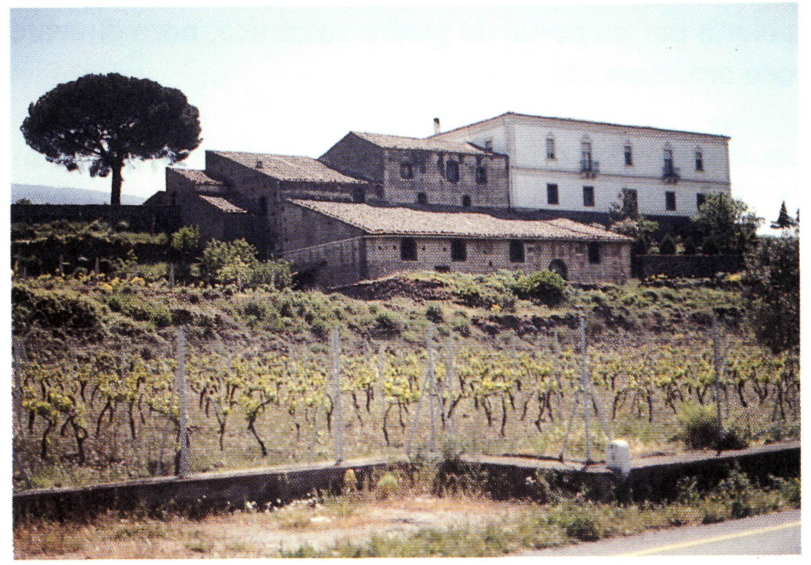

Fig. 11.- Vivienda con "palmento" y bodega anejas en el territorio de Randazzo, en la finca Fisauli. Destaca el diferente tratamiento de la parte residencial respecto de la productiva y la organización altimétrica en el conjunto del edificio.

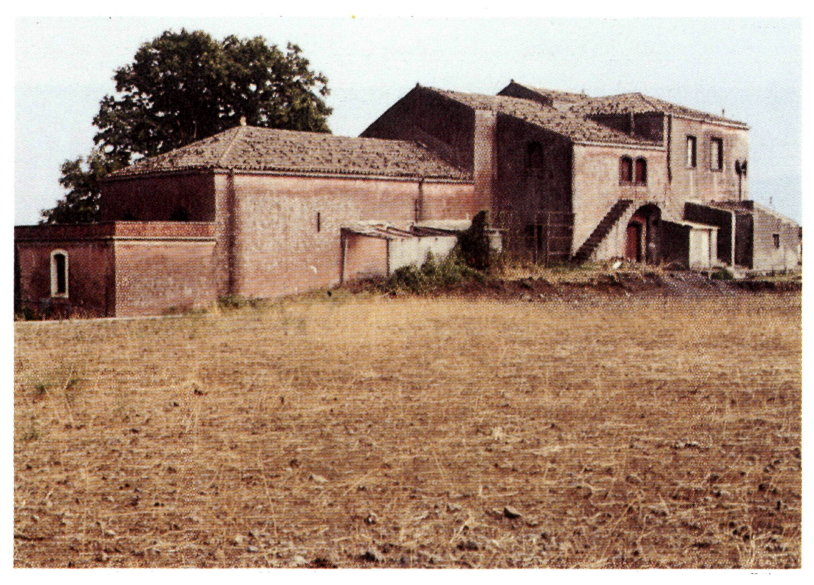

Fig. 12.- Complejo vinicola en el territorio del Piamonte étneo.

lar, en las estancias de los señores se puede adivinar una influencia, más o menos relevante, de la arquitectura culta. Hay que notar cómo esta connotación, diferente del tema formal, se puede distinguir incluso cuando la casa del señor y la bodega/palmento se encuentran en un mismo cuerpo constructivo. Esto demuestra el diferente valor representativo atribuido a cada una de las partes de edificio y, como consecuencia, también una diferente aportación de figuras profesionales y maestros de la construcción (Fig. 11).

Los complejos arquitectónicos de las zonas vinícolas se presentan, en general, de un modo muy articulado y son, con frecuencia, el fruto de sucesivos añadidos. En cualquier caso, prevalece una disposición de los edificios a adaptarse perfectamente a la morfología del suelo, especialmente accidentada en las áreas vitícolas que se encuentran en cotas más elevadas.

El material que por lo general se emplea como techo, formado por diferentes tipos de tejas, representa un importante elemento de unificación formal de los distintos edificios que forman el conjunto (Fig. 12).
6. La situación actual de los edificios históricos para la producción del vino en la región del Etna

\section{I Los edificios históricos y las actuales exigencias de producción de las empresas vinicolas}

En las zonas de la región del Etna y en las empresas en las que, todavía hoy, la vid y el vino representan un horizonte productivo importante, los antiguos palmentos y las bodegas se usan, hoy en día, para el mismo fin que en los orígenes. En algunos casos se han modificado y adaptado, para afrontar específicas exigencias funcionales, pero, en general, no han padecido excesivas manipulaciones.

Algunos estudios recientes han demostradola funcionalidad de los edificios tradicionales también en las condiciones actuales de producción vinícola, dentro de un tejido productivo que contempla una gran fragmentación de la propiedad agraria y una dominante pequeña-mediana empresa vitivinícola (Failla y Nicolosi Asmundo, 1984; Casconeet al., 1996). Además, en la actualidad, se nota una nueva tendencia a valorar los edificios productivos tradicionales en el ámbito de empresas orientadas hacia la producción de vinos de calidad y que quieren responder, de un modo articulado y completo, a la demanda de los consumidores (Di Fazio e Pennisi,1995).

En Italia, la actitud del consumidor hacia el vino, de hecho, ha cambiado enormemente con respecto al pasado. La cantidad de vino consumido en los últimos veinticinco años se ha dividido por la mitad, mientras que ha crecido muchísimo la demanda de calidad. Se bebe menos, pero se bebe mejor. Además, hoy el consumidor mira el vino como un producto lleno de cultura: está atento a las informaciones que a él se refieren, se documenta, desea conocer los sitios y las empresas que lo producen. Esta actitud, unida al reciente aumento considerable del turismo rural, ha llevado a un número creciente de personas a visitar las regiones vitícolas, y a comprar el vino directamente de fábrica, ligando el hecho de comprar el vino a una ocasión de descanso y recreo.

La región del Etna es una de las principales áreas geográficas sicilianas dedicadas a la producción de vino de denominación de origen controladay, en este ámbito, se ha implantado una nueva orientación de la producción hacia vinos de alta calidad. La mayor parte de esas empresas encuentran hoy numerosos motivos de interés y de oportunidad en el reaprovechamiento de las bodegas y de los edificios tradicionales, tanto por los aspectos directamente ligados a la actividad productiva, como por otros que se encuentran relacionados con ella (Cascone et al., 1996).

Las características arquitectónicas y_constructivas de las bodegas tradicionales ofrecen ventajas ciertas en lo que se refiere a los parámetros termohigrométricos, garantizando niveles estables y cercanos a los óptimos a pesar de las 
elevadas temperaturas y las considerables variaciones de los parámetros microclimáticos externos que se verifican durante largos períodos del año. Estas ventajas tienen incluso hoy gran importancia, sobre todo si se realiza el envejecimiento del vino en tonel o en botella, o en recipientes que no pueden ser termoacondicionados y que, por lo tanto, precisan un cuidadoso control ambiental de los locales de conservación. Además, a pesar de que ya no se prensa con los pies, los niveles destinados en los palmentos originales a tal fin pueden conservar su función original, albergando a las modernas máquinas utilizadas normalmente para la fabricación del vino

En los palmentos tradicionales que llenan el territorio étneo, la presencia frecuente de las antiguas prensas de madera -bien conservadas, en muchos casos incluso en funcionamiento o en pleno uso - representa, desde el punto de vista histórico-cultural, uno de los mayores puntos de interés de los palmentos étneos. Como el nivel de prensado mecánico ya no se puede adaptar fácilmente debido a la tecnología ni se puede utilizar para otras funciones, al no ser fácil ni conveniente retirar las prensas, mantiene todavía hoy una razón de conservación, precisamente por el valor cultural y por el importante atractivo que representa para los visitantes. De hecho, hoy las empresas que producen vino de D.O.C. están especialmente interesadas en documentar y recalcar el enraizamiento en una tradición plurisecular. El vino, en realidad, tiene que considerarse no sólo el producto de una empresa, sino el producto de una cultura: por lo tanto, el contenido histórico y cultural de la región que lo produce pasa a formar parte, no solamente de la imagen de la empresa productora, sino de la del mismo vino. Las bodegas históricas constituyen un documento físico, visible y concreto de tal enraizamiento.

6.2 La recuperación de los edificios históricos y la promoción de las empresas y de las regiones vinicolas

Las empresas que tienen una presencia arraigada en algún territorio de producción consideran el valor de los editicios tradicionales como parte de su imagen y de la del mismo vino, representándolos, por ejemplo, en la etiqueta del vino embotellado, en el material publicitario e informativo o en las diversas formas de comunicación empresarial.

Esta nueva actitud se ha difundido a lo largo de todo el territorio nacional y no se refiere sólo a las empresas vinícolas más ancestrales. En Italia, de hecho, desde hace algunos años también las empresas vinícolas nuevas tienden a realizar parte del núcleo productivo en los edificios tradicionales. Esta tendencia, en la zona del Etna, está motivada, además de para las demás regiones antes citadas, por otras razones, dictadas por las normas urbanísticas vigentes. Una buena parte de los viñedos que están dentro del área productiva definida dentro del marco que caracteriza la D.O.C. "Etna" se encuentran dentro del territorio del Parque Regional del Etna, en un área de gran relevancia paisajística o, en definitiva, en áreas sujetas a restricciones en cuanto a la construcción.. La consecuencia es que los edificios nuevos -con las dimensiones adecuadas- que habría que construir están sujetos a impedimentos o a largos procesos de final incierto; y esto es precisamente lo que fuerza a los empresarios a que prefieran adaptarse a construcciones ya hechas, antes que acometer la realización de otras nuevas.

Desde hace varios años, la promoción de los vinos fabricados en Sicilia la lleva a cabo un ente específico, el Instituto Regional para la Vid y el Vino. Recientemente, se han llevado a cabo iniciativas para ligar la promoción del vino siciliano a la del turismo rural en las áreas vinícolas, por medio de la determinación de recorridos del vino en áreas de ancestral tradición productiva, donde el paisaje vinícola es especialmente bonito. En el área del Etna, de todas formas, la iniciativa necesita todavía una adecuada infraestructura de los itinerarios, una mayor participación de las empresas productoras y, sobre todo, una mayor sensibilización hacia el patrimonio arquitectónico y cultural que documenta la tradición vinícola de la región.

\subsection{La recuperación y la reutilización de los edificios rurales abandonados en la región del Etna. Iniciativas actuales y perspectivas}

En las zonas donde la viticultura ha desaparecido, a causa de una general decadencia de la agricultura o por una modificación de los objetivos productivos de las empresas, los palmentos han sido, total o parcialmente, abandonados. Igualmente difundido, de los años ' 50 a los nuestros, ha estado el abandono de las residencias rurales, debido a la migración de la población rural hacia las ciudades y a un generalizado cambio de los estilos de vida que han hecho preferible la estancia en centros urbanos. Este fenómeno ha afectado inevitablemente a muchas de las residencias rurales de los señores que se encontraban en las grandes posesiones. Una gran parte del patrimonio arquitectónico rural, que sólo se puede conservar con una permanencia estable, corre el peligro de ir a la ruina y desaparecer

Hasta ahora han faltado estrategias e intervenciones públicas para conservar el patrimonio arquitectónico rural que demostrasen solidez e ideas claras. Sólo desde hace algunos años se ha visto la necesidad, en esta parte de Sicilia, de actuar con medidas de salvaguarda, como han puesto en evidencia diversos estudios y trabajos (Failla et al., 1997; Failla, 1995; Fichera, 1997). El conocimiento y la clasificación del patrimonio constituyen el primer paso de conservación. En lo que se refiere a la región del Etna, en el ámbito universitario se han realizado diversos estudios sobre la arquitectura rural, tanto por parte del departamento de Arquitectura como del I.T.C.R de la Universidad de Catania, pero falta todavía -incluso en los territorios unidos al Parque Regional del Etna- un catálogo de los edificios rurales de interés histórico. Éste, para ser realizado, nece- 
sita la colaboración y la financiación de los entes territoriales.

La protección del patrimonio arquitectónico rural, en definitiva, no se puede limitar a pocos edificios destacados, sinoque tiene que abarcar el patrimonio completo. El poderse llevar a cabo depende de que el patrimonio rural se considere un recurso territorial; un recurso que puede ser empleado completamente por medio de unos usos compatibles y cuya presencia, del mismo modo, contribu- ye a determinar la vocación preferente del territorio en el que se encuentran.

Recientemente el Instituto de Topografía y Construcciones Rurales de Catania y el DISTAFA de la Universidad de Reggio Calabria han emprendido iniciativas conjuntas en ese aspecto, con el fin de estudiar el potencial de reutilización de los edificios rurales abandonados en las áreas desfavorecidas, convirtiéndose en promotores de programas de investigación en este sector, tanto en el marco nacional como internacional.
(1) N. del T. "La palabra palmento tiene traducción como lagar o jaraiz y otros términos, que varían según la región vinícola española. Por esta razón, se ha preferido conservar el término italiano".

(2) "Después de exprimir por segunda o tercera vez, las cascas se ven reducidas a un estado tal de sequedad que se espera, inútilmente, el mismo resultado utilizando la prensa de percusión de Revillon, con tornillo único y central (..) y también con la otra prensa, más imperfecta, con dos tornillos de madera y que se llama calabresa; con cuyos mecanismos se exprime incluso el orujo de las aceitunas (..) El conso ofrece la ventaja de exprimir grandes cantidades de casca con menos mano de obra, con menores gastos y sin complejos mecanismos. En realidad, para conseguir de una manera incompleta el efecto de un conso que prensa $16.000 \mathrm{~kg}$ de uva, se necesita el trabajo de 8 ó 10 prensas a percusión, cada una de las cuales necesitará, al menos, el trabajo de dos obreros, por lo que, en total, serán 16 ó 20 , mientras el conso lo hacen funcionar solamente 3 ó 4 personas y, en algunos casos, cuando sus dimensiones son reducidas, serían suficientes incluso dos trabajadores".
(3) "De lo anterior sigue que la viga del conso constituye ahora una palanca de $2^{\circ}$ tipo y una de $1^{\circ}$. En el primero de los casos el tornillo es la potencia, las cascas la resistencia y el extremo b el quicio o punto de apoyo. En el segundo caso, el quicio está representado por la escalera, la resistencia por el extremo h y la potencia por el tornillo. Y como por la ley de la mecánica la potencia o la resistencia aumenta en proporción directa de su respectivo brazo de potencia o de resistencia, así, en ambas circunstancias, siendo el brazo de la potencia mucho más largo que el de la resistencia, resulta que la potencia superará con ventaja a la resistencia gracias a una fuerza mucho mayor". "Éstas son las razones por las que el conso, aun siendo un invento antiguo y rústico, no deja de ser un aparato sencillo, útil y de gran importancia económica; no sólo, sino que frente a los demás mecanismos parece que ofrece requisitos más estables y convenientes. Por la belleza, a lo mejor en un primer momento uno se siente estimulado a condenar un invento rústico, que se presenta tan poco sofisticado como simple; pero examinándolo en sus detalles con los ojos de la razón y con el del cálculo, se nos muestra, cada vez más, como un instrumento muy valioso y muy conveniente en la práctica".

\section{BIBLIOGRAFIA}

(1) Adam J.P., (1984). La Construction Romaine. Materiaux et techniques. Grands Manuels Picard, Paris.

(2) Caruso G. (1869). Memoria sulla viticoltura e vinificazione ovvero il presente e l'avvenire enologico dell'Italia meridionale. Memorie scientifiche premiate per concorso dal Congresso Agrario di Catania nel 1868. Stamperia di Giovanni Lorsnaider, Palermo.

(3) Cascone G., Di Fazio S., Pennisi P. (1996). Design concepts for the rehabilitation of traditional wineries in Sicily. In: Proceedings of the International Seminar of the Second Technical Section of CIGR on "New uses for old rural buildings in the context of landscape planning", Piacenza, Italy; vol. 2, pp. 261-268.

(4) Cascone G., Di Fazio S., Pennisi P. (1994). Il recupero degli edifici tradizionali in zona sismica. Materiali, tecniche costruttive e tipi di intervento. In: Atti del Seminario AIGR su "Il recupero dell'edilizia rurale nel contesto territoriale", Sassari, vol.3; pp.723-734.
(5) Di Fazio S. e Pennisi P. (1995). Edifici per la produzione e la conservazione di vini a D.O.C. in Sicilia. In: "Costruzioni e impianti per la conservazione e trasformazione dei prodott $i$ agricoli”, Rivista di Ingegneria Agraria, Quaderno n. 18; pp. $179-193$.

(6) Failla A., Cascone G., Di Fazio S. (1987). Architettura rurale nel territorio etneo. In: " $L$ 'architettura rurale nelle trasformazioni del territorio in Italia", Laterza editore, Bari; pp.491-509.

(7) Failla A., Nicolosi Asmundo C. (1984). Impianti enologici tradizionali ed esigenze di rinnovamento nel comprensorio etneo. In: Genio Rurale, n. 1; pp.35-42.

(8) Failla A. (1995). L'edilizia agricolanel parco dell'Etna. In: Atti del Convegno su "Il Parco dell'Etna. Ruolo dell'architettura nell'ambiente"; Ordine degli Architetti della provincia di Catania, Bronte, 9 settembre 1994: pp. $37-53$ 
(9) Fichera C.R. (1997). Tutela e valorizzazione degli edifici rurali storici e tradizionali. in: Genio rurale, n. 1; pp.63-68.

(10) Iachello E. (1991). Il vino e il mare. "Trafficanti" siciliani tra ' 700 e' 800 nella Contea di Mascali. Giuseppe Maimone Editore, Catania.

(11) La Guzza A., La Guzza R., Lo Giudici S. (1994). Linguaglossa, Architettura rurale. 'U Pammentu. Quaderni del Centro UNESCO Catania. Euroguide.

(12) Palumbo G. (1991). Le residenze di campagna nel versante orientale dell'Etna. Università di Catania, Documenti del Dipartimento di Architettura e Urbanistica, n.6.
(13) Pastena B. (1989). La civiltà della vite in Sicilia. Regione Siciliana, Istituto Regionale della Vite e del Vino. Edizioni Leopardi, Palermo.

(14) Sestini D. (1812). Dei vini di Mascali Città della Sicilia. Memoria presentata all' Accademia dei Georgofili, Firenze, 6 Febbraio 1812. Archivio dell' Accademia dei Georgofili, Ms., Busta 63-64, nn. 440,441,443. Pubblicato in: Sestini D., Memorie sui vini siciliani. Sellerio editore, Palermo, 1991; pp.43-54

(15) Sanfilippo E.D (1993). La costruzione del paesaggio antropico etneo. In: AA.VV., Etna, il vulcano e l'uomo. Maimone editore. Catania.

\title{
Publicación del Instituto Eduardo Torroja - CSIC
}

\author{
Número monográfico de INFORMES
}

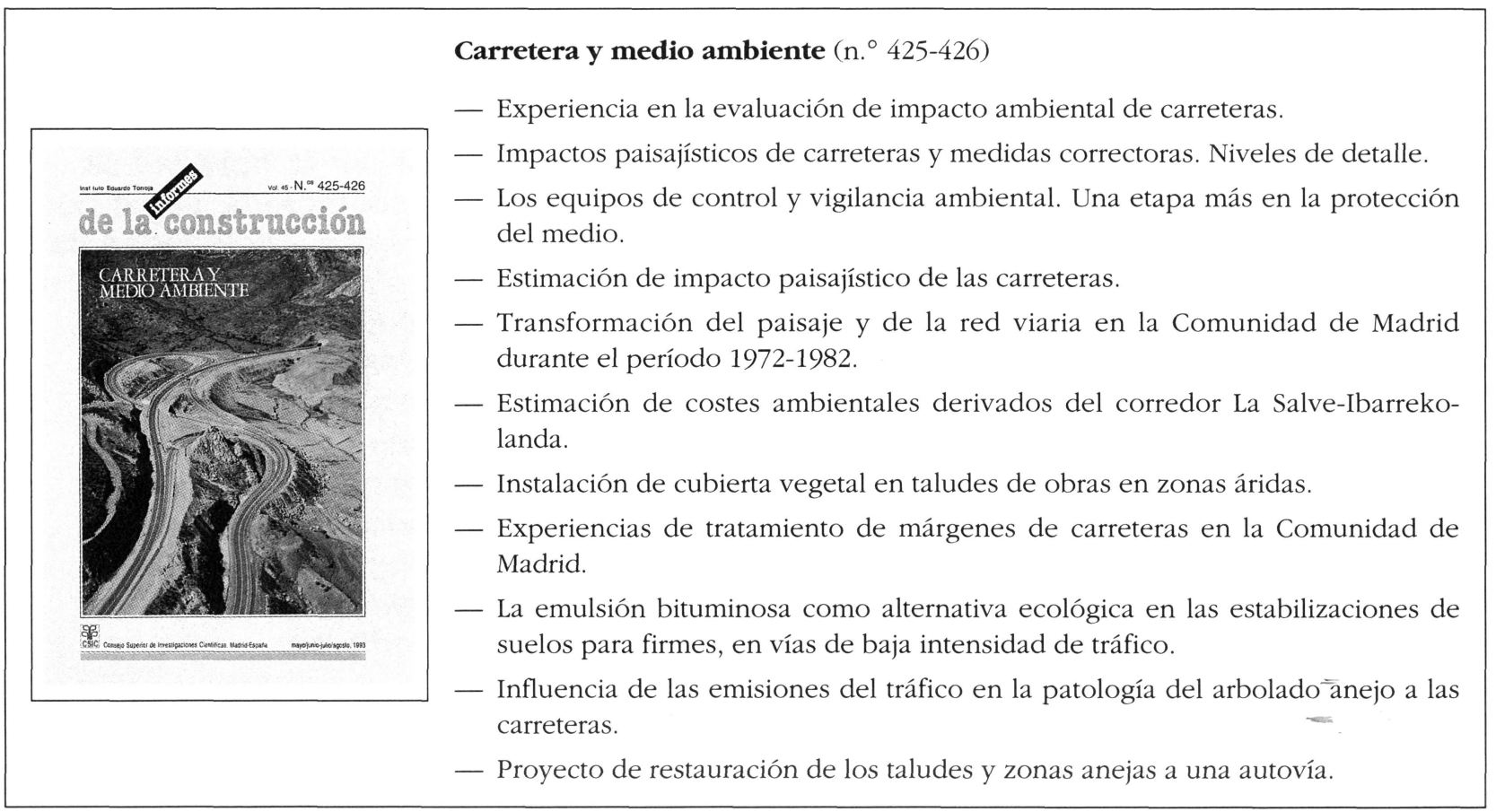

(c) Consejo Superior de Investigaciones Científicas 